\title{
First record of Poecilochirus necrophori (Acari: Mesostigmata: Parasitidae) from Turkey and its importance in forensic acarology
}

\author{
Kamila ONDREJKOVÁ1 (D), Gökhan EREN ${ }^{2,3}$ [D, Mustafa AÇICI ${ }^{2}$ (D) \\ ${ }^{1}$ Department of Zoology, Faculty of Natural Sciences, Comenius University, Ilkovičova 6, 84215 Bratislava, Slovakia \\ 2 Department of Parasitology, Faculty of Veterinary Medicine, Ondokuz Mayıs University, Samsun, Turkey \\ ${ }^{3}$ Corresponding author: gokhaneren54@gmail.com
}

Received: 9 April 2021

Accepted: 18 July 2021

Available online: 31 July 2021

ABSTRACT: Poecilochirus necrophori Vitzthum, 1930 is a Palearctic distributed species, which deutonymphs are phoretic on some burying beetles (Coleoptera: Silphidae). The mites use adult beetles for transport to carcasses where the deutonymphs moult into adults and both mites and beetles feed and reproduce. A life cycle of Poecilochirus species is synchronized with their phoronts and they can be used in a forensic acarology as indicators of post mortem interval. We present the first record of $P$. necrophori from Turkey. Phoretic deutonymphs of $P$. necrophori were found on the beetle Nicrophorus vespillo (L.) (Coleoptera: Silphidae) in Sakarya province. The deutonymphs were also found on carcasses of marten (Marten sp.) and mole (Talpa sp.) from Sakarya, Turkey. Moreover, a significance of Poecilochirus species in forensic acarology is briefly discussed.

Keywords: Parasitidae, Poecilochirus necrophori, phoretic mites, carcasses, Turkey

Zoobank: http://zoobank.org/B0359A97-7806-4A39-889B-4540972977F6

\section{INTRODUCTION}

Poecilochirus necrophori Vitzthum, 1930 is a phoretic mite species living in association with carrion and burying beetles (Baker and Schwarz, 1997). Adults can be found on animal and human carcasses, while deutonymphs are phoretic on adult beetles. Deutonymphs can also be found on the carcasses, until they attach to their phoront (Schwarz and Walzl, 1996). The deutonymphs of this species prefer a beetle Nicrophorus vespillo (L.) as a host, however, they can use different beetle species if their preliminary host is not available (Nehring et al., 2017). The nature of a relationship between Poecilochirus mites and their host beetles depends on a number of conditions and can vary from parasitic or competitive through commensal to mutualistic (Nehring et al., 2017; Sun et al., 2019).

Due to their specificity, abundance, diversity, and frequent occurrence on carcasses, Poecilochirus species are of great importance to be used as indicator species in forensic acarology (Perotti et al., 2009, Pérez-Martínez et al., 2019). Despite the knowledge regarding the presence of mites in corpses, and their role in the decomposition of carcasses for a long period of time, their importance in forensic research has only been recognized in recent decades (Braig and Perotti, 2009; Medina et al., 2013, SaloñaBordas and Perotti, 2014; Saloña-Bordas and Perotti, 2019). The only way for Poecilochirus species to get to the carcass is a phoresy (Perotti et al., 2009). They can change hosts on the carcass and even feed and reproduce on the carcass when there is no host present. However, as the mites cannot move to new carrion on their own, the offspring must reach the phoretic stage before the corpse rots and must attach to new host insects (Schwarz and Koulianos, 1998). Therefore, mites reproduce much faster than their carriers which makes them better timeline markers than insects in forensic research (Perotti et al., 2009).

Hyatt (1980) synonymized this species with Poecilochirus carabi G. et R. Canestrini, 1882 due to variability of characters (e.g. shape of a transverse sclerotized sternal band, size of dorsal shields, length of setae) used for identification of these species. However, subsequent studies (Müller and Schwarz, 1990, Schwarz et al., 1991, Schwarz and Walzl, 1996) have shown, that both species are behaviorally and reproductive isolated and Baker and Schwarz (1997) reviewed the taxonomic status of both species.

Poecilochirus necrophori is known from Europe and Asia (Karg, 1993), it is probably a Palearctic species with the same distribution as its main host $N$. vespillo, although it may accidentally be found on other silphid beetles (Springett, 1968). Canitz et al. (2021) found this species in Europe and Kazakhstan.

The aim of the current study is to report P. necrophori based on the materials collected on animal carcasses of Martes sp. (Carnivora: Mustelidae) and Talpa sp. (Eulipotyphla: Talpidae) and beetle (N. vespillo) for the first time in Turkey.

\section{MATERIALS AND METHODS}

Mites were collected from animal carcasses (Martes sp. and Talpa sp.) and from host beetle (N. vespillo). The mites and phoretic carrier were photographed on the spot with a camera (Nikon P610). Subsequently, the samples were preserved in $70 \%$ ethanol. The mite samples were kept in formaldehyde for 24 hours to be translucent, then identified under a Fluorescence Upright Microscope (Nikon Eclipse 80i). Photographs were taken with the Mdx4-t 
model microscope camera. The measurements of setae, podonotum and opisthonotum were taken by the MShot Image Analysis System program.

Identifications of beetle and mites were done according to the keys published by Ciftci et al. (2018) and Mašán (1999), respectively. The specimens are deposited in the Parasitology Laboratory of Department of Parasitology, Faculty of Veterinary Medicine of Ondokuz Mayıs University (Samsun, Turkey).

Material examined: Poecilochirus necrophori, 25 deutonymphs phoretic on N. vespillo, 13.07.2019, Sakarya, $41^{\circ} 3^{\prime} 54.06^{\prime \prime N}, 30^{\circ} 39^{\prime} 19.00^{\prime \prime}$ E, altitude 60 m, leg. G. Eren; 11 deutonymphs on carcasses, ibidem, collected on animal carcasses (Martes sp. and Talpa sp.) and on beetle $(N$. vespillo that was feeding on carcass).
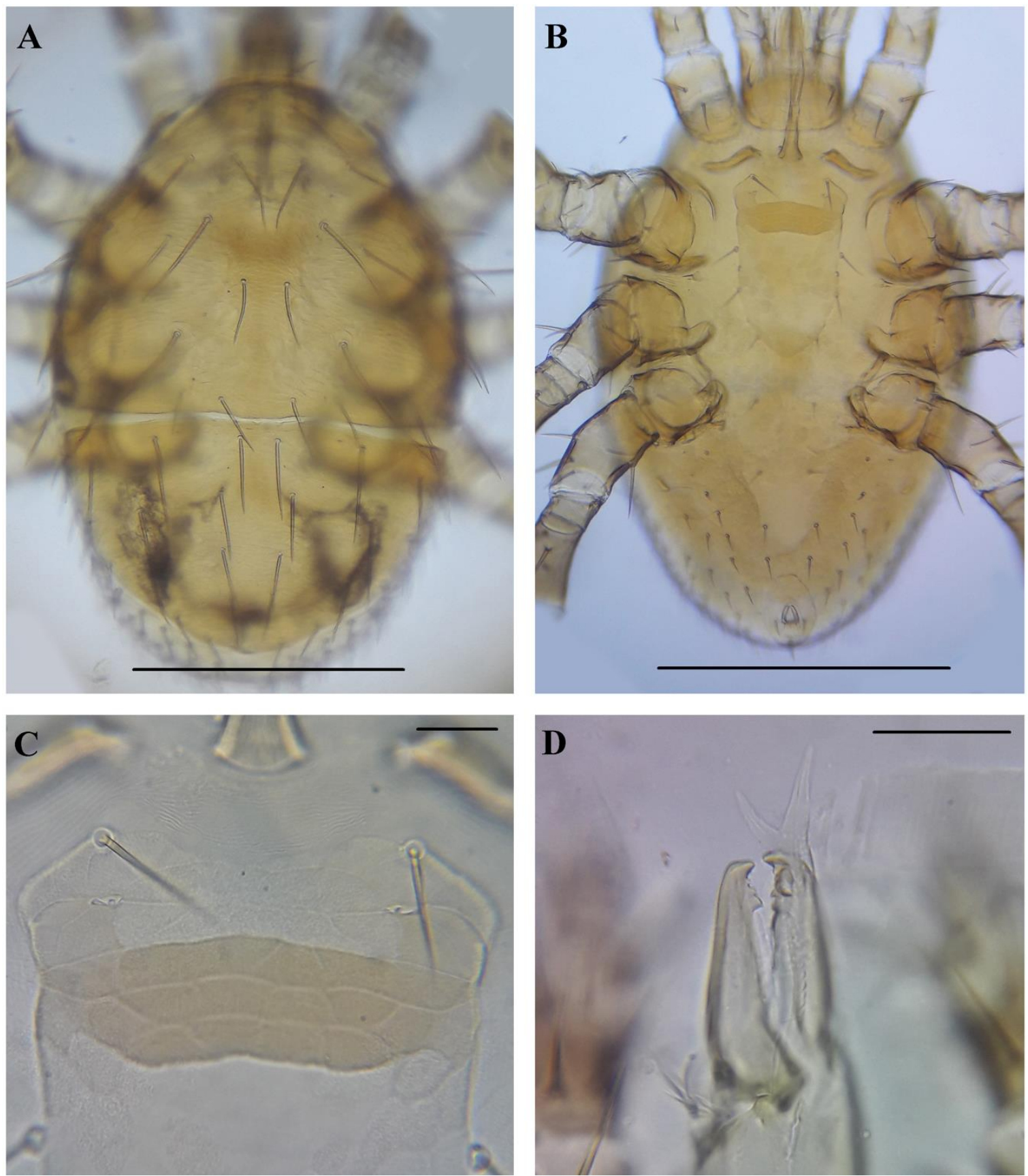

Figure 1. Poecilochirus necrophori (Deutonymph) A. Dorsal viewl, B. Ventral view (scale bars $=500 \mu \mathrm{m}$ ), C. Sclerotized transverse sternal bands (scale bar $=50 \mu \mathrm{m})$, D. Cheliceral digitus fixus (scale bar $=40 \mu \mathrm{m})$. 


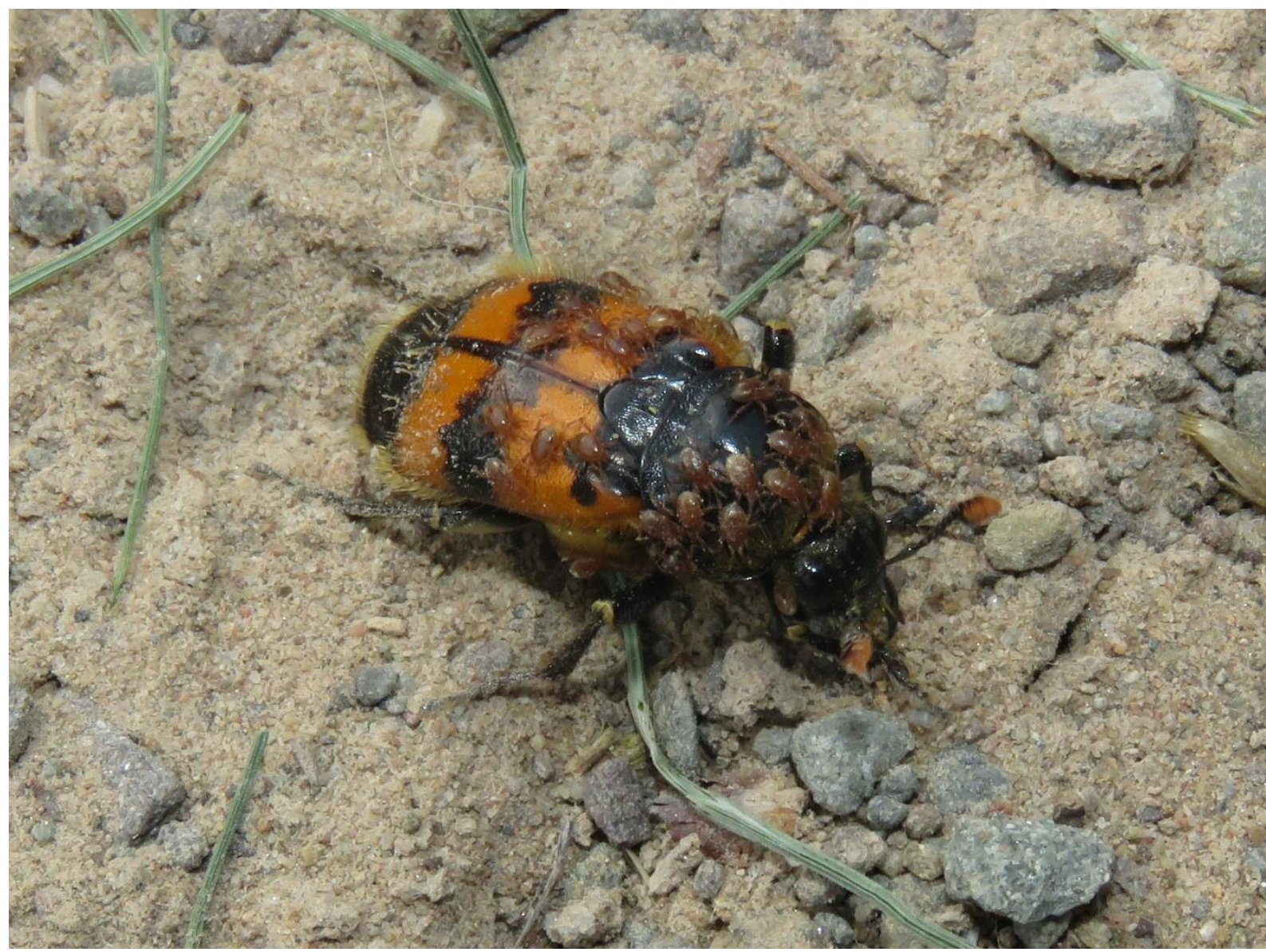

Figure 2. Poecilochirus necrophori (Deutonymph) on its phoront Nicrophorus vespillo (from the marten (Martes sp.) carcass).

\section{DISCUSSION}

Carcasses are dynamic and temporary ecosystems with a relatively short duration, which are attractive for different trophic groups of mites. All those mites had to develop strategies to migrate to new carcasses after the first one is reduced and the phoresy is one of these strategies. Most of the mites regularly found on carcasses belong to families Ascidae, Laelapidae, Macrochelidae, Parasitidae and Uropodidae and they can be used as indicator species in forensic studies (Pérez-Martínez et al., 2019). Over 100 species of mites associated with human and animal carcasses have been reported so far (Perotti et al., 2009). Poecilochirus species are one of the most abundant gamasid mites found in carcasses, however, different species may occur at the different stages of the decomposition (Pérez-Martínez et al., 2019, Saloña-Bordas and Perotti, 2019). Several Poecilochirus species (P. austroasiaticus, P. carabi, P. davydovae and P. subterraneus) have been already reported on human carcasses, $P$. mrciaki on a pig carcass, $P$. necrophori on a mouse carcass and Poecilochirus sp. on seal, rat and rabbit carcasses (Lord and Burger, 1984; De Jong and Chadwick, 1999; Braig and Perotti, 2009; Medina et al., 2013; Saloña-Bordas and Perotti, 2014; Saloña-Bordas and Perotti, 2019).

In this study, the mites were collected together with $N$. vespillo feeding from marten (Martes sp.) and mole (Talpa sp.) carcasses, as well as mites walking directly on the carcass.
The observations and measurements of collected specimens are in agreement with those reported by Baker and Schwarz (1997) (Table 1). In addition to morphological and molecular methods (which couldn't be used in this case due to the fact that our material was processed in formaldehyde), behavioral methods can be used to identify this species among others Poecilochirus species. Many studies (Müller and Schwarz, 1990, Schwarz et al., 1991, Nehring et al., 2017, Canitz et al., 2021) have confirmed that the species $P$. necrophori is specialized to the beetle species $N$. vespillo, on which our individuals were found.

Table 1. Length of dorsal setae and dorsal shields of Poecilochirus necrophori (Deutonymph)

\begin{tabular}{lll}
\hline Seta / shield & Range $(\boldsymbol{\mu m})$ & Mean \\
\hline$Z 1$ & $150-150$ & 150 \\
\hline$s 4$ & $160-180$ & 167.5 \\
\hline$J 1$ & $110-135$ & 134.5 \\
\hline$s 5$ & $150-165$ & 152.7 \\
\hline$z 5$ & $260-280$ & 272 \\
\hline$r 3$ & $350-365$ & 353 \\
\hline opisthonotum & $420-475$ & 449.5 \\
\hline podonotum & $575-600$ & 595 \\
\hline
\end{tabular}


Till now, only four Poecilochirus species were known and described from Turkey (Ramaraju and Madanlar, 1998). None of them was found on the carcass and none of these species possesses apomorphies, which are characteristic for Poecilochirus deutonymphs. These characters include the sternal shield with the sclerotized transverse sternal band and the membranous process at the tip of the fixed digit of chelicerae (Hyatt, 1980).

In the present study, Poecilochirus mites are evaluated in terms of forensic acarology in Turkey and P. necrophori is reported from Turkey for the first time. Additionally, further studies are essential in order to obtain more detailed knowledge for the use of these mites in forensic acarology in Turkey.

\section{Authors' contributions}

Kamila Ondrejková: Conceptualization (equal), data curation, formal analysis (equal), resources (equal), visualization (equal), writing - original draft (supporting), writing - review \& editing (lead). Gökhan Eren: Conceptualization (equal), investigation, formal analysis (equal), methodology (equal), resources (equal), visualization (equal), writing - original draft (lead), writing - review \& editing (supporting). Mustafa Açıcı: Conceptualization (equal), methodology (equal), supervision, visualization (equal), writing - original draft (supporting), writing review \& editing (supporting).

\section{Statement of ethics approval}

Not applicable.

\section{Funding}

There is no fund for the present study.

\section{Conflict of interest}

The authors do not have conflict of interest.

\section{REFERENCES}

Baker, A.S. and Schwarz, H.H. 1997. Morphological differences between sympatric populations of the Poecilochirus carabi complex (Acari: Mesostigmata: Parasitidae) associated with burying beetles (Silphidae: Nicrophorus). Systematic Parasitology, 37: 179-185. doi: 10.1023/A:1005822702267

Braig, H.R. and Perotti, M.A. 2009. Carcases and mites. Experimental and Applied Acarology, 49 (1): 45-84. doi: 10.1007/s10493-009-9287-6

Canitz, J., Sikes, D.S., Knee, W., Baumann, J., Haftaro, P., Steinmetz, N., Nave, M., Eggert, A.-K., Hwang, W. and Nehring, V. 2021. Cryptic diversity within the Poecilochirus carabi mite species complex phoretic on Nicrophorus burying beetles: phylogeny, biogeography, and host specificity. bioRxiv. doi:10.1101/2021.05.20.443311

Ciftci, D., Ruzicka, J., Hasbenli, A. and Sahin, Ü. 2018. The large carrion beetles (Coleoptera: Silphidae) of Tur- key: a review with a new species record. Zootaxa, 4441 (3): 555-591.

doi:10.11646/zootaxa.4441.3.10

De Jong, G.D. and Chadwick, J.W. 1999. Decomposition and arthropod succession on exposed rabbit carrion during summer at high altitudes in Colorado, USA. Journal of Medical Entomology, 36 (6): 833-845.

doi:10.1093/jmedent/36.6.833

Hyatt, K.H. 1980. Mites of the subfamily Parasitinae (Mesostigmata: Parasitidae) in the British Isles. Bulletin of the British Museum (Natural History), Zoology series, 38 (5): 237-378.

Karg, W. 1993. Acari (Acarina), Milben. Parasitiformes (Anactinochaeta) Cohors Gamasina, Leach, Raubmilben. 2. Überarbeitete Auflage. Die Tierwelt Deutschlands, 59. Gustav Fischer Verlag, JenaStuttgart, Germany and New York, USA 523 pp. [In German]

Lord, W.D. and Burger, J.F. 1984. Arthropods associated with harbor seal (Phoca vitulina) carcasses stranded on islands along the New England Coast. International Journal of Entomology, 26: 282-285.

Mašán, P. 1999. Mites (Acarina) associated with burying and carrion beetles (Coleoptera, Silphidae) and description of Poecilochirus mrciaki sp. n. (Mesostigmata, Gamasina). Biologia, Bratislava, 54: 515-524.

Medina, A.G., Herrera, L.G., Perotti, M.A. and Ríos, G.J. 2013. Occurrence of Poecilochirus austroasiaticus (Acari: Parasitidae) in forensic autopsies and its application on postmortem interval estimation. Experimental and Applied Acarology, 59 (3): 297-305.

doi: 10.1007/s10493-012-9606-1

Müller, J.K. and Schwarz, H.H. 1990. Differences in carrierpreference and evidence of reproductive isolation between mites of Poecilochirus carabi (Acari, Parasitidae) living phoretically on two sympatric Necrophorus species (Coleoptera, Silphidae). Zoologische Jahrbücher, Abteilung für Systematik, Ökologie und Geographie der Tiere, 117: 23-30.

Nehring, V. Müller, J.K. and Steinmetz, N. 2017. Phoretic Poecilochirus mites specialize on their burying beetle hosts. Ecology and Evolution, 7 (24): 10743-10751. doi: 10.1002/ece3.3591

Pérez-Martínez, S., Moraza, M.L. and Saloña-Bordas, M.I. 2019. Gamasina mites (Acari: Mesostigmata) associated with animal remains in the mediterranean region of Navarra (Northern Spain). Insects, 10 (1): 5 doi: 10.3390/insects10010005

Perotti, M.A., Braig, H.R. and Goff, M.L. 2009. Phoretic mites and carcasses: Acari transported by organisms associated with animal and human decomposition. In: Current concepts in forensic entomology. Amendt, J., Goff, M.L., Campobasso, C.P. and Grassberger, M. (Eds). Springer, Dordrecht, The Netherlands, 69-91. 
doi: 10.1007/978-1-4020-9684-6_5

Prevett, P. 1953. Notes on the feeding habits and life history of Galeruca tanaceti L. (Col., Chrysomelidae). Entomologist's Monthly Magazine, 89: 292-293.

Ramaraju, K. and Madanlar, N. 1998. Four new Poecilochirus G. \& R. Canestrini (Acarina: Parasitidae) species from Turkey. Turkish Journal of Entomology, 22 (1): 3-17.

Saloña-Bordas, M.I. and Perotti, M.A. 2014. First contribution of mites (Acari) to the forensic analysis of hanged corpses: A case study from Spain. Forensic Science International, 244: e6-e11.

doi: 10.1016/j.forsciint.2014.08.005

Saloña-Bordas, M.I. and Perotti, M.A. 2019. First record of Poecilochirus mrciaki Mašán, 1999 (Acari, Parasitidae) and its phoretic carriers in the Iberian Peninsula. Acarologia, 59 (2): 242-252.

doi: 10.24349/acarologia/20194328

Schwarz, H.H. and Koulianos, S. 1998. When to leave the brood chamber? Routes of dispersal in mites associated with burying beetles. Experimental and Applied Acarology, 22 (11): 621-631. doi: 10.1023/A:1006054604520

Schwarz, H.H. and Walzl, M.G. 1996. Pairing, oviposition and development in two sibling species of phoretic mites (Acari: Mesostigmata: Parasitidae: Poecilochirus spp.) associated with burying beetles (Coleoptera: Silphidae: Nicrophorus spp.). Journal of Natural History, 30 (9): 1337-1348.

doi: $10.1080 / 00222939600771251$

Schwarz, H.H., Müller, J.K. and Baker, A. 1991. Genetic differentiation between deuteronymphs of Poecilochirus carabi (Mesostigmata, Parasitidae) living on sympatric Necrophorus species (Coleoptera, Silphidae). In: Modern Acarology (Vol. 2) Dusbábek, F. and Bukva, V. (Eds). Academia, Prague, Check Republic and SPB Academic Publishing, The Hague, the Netherlans, 431-436.

Springett, B.P. 1968. Aspects of the relationship between burying beetles, Necrophorus spp. and the mite, Poecilochirus necrophori Vitz. The Journal of Animal Ecology, 37 (2): 417-424.

doi: $10.2307 / 2957$

Sun, S.J., Horrocks, N.P.C. and Kilner, R.M. 2019. Conflict within species determines the value of a mutualism between species. Evolution Letters, 3 (2): 185-197. doi: 10.1002/evl3.109

Edited by: Sebahat K. Ozman-Sullivan

Reviewed by: Four anonymous referees

Citation: Ondrejková, K., Eren, G. and Açıcı, M. 2021. First record of Poecilochirus necrophori (Acari: Mesostigmata: Parasitidae) from Turkey and its importance in forensic acarology. Acarological Studies, 3 (2): 96-100. 